\title{
A novel short $L$-arginine responsive protein-coding gene (laoB) antiparallel overlapping to a CadC-like transcriptional regulator in Escherichia coli 0157:H7 Sakai originated by overprinting
}

Sarah M. Hücker ${ }^{1,5}$, Sonja Vanderhaeghen ${ }^{1}$, Isabel Abellan-Schneyder ${ }^{1,4}$, Romy Wecko', Svenja Simon², Siegfried Scherer ${ }^{1,3}$ and Klaus Neuhaus ${ }^{1,4^{*}}$ (D)

\begin{abstract}
Background: Due to the DNA triplet code, it is possible that the sequences of two or more protein-coding genes overlap to a large degree. However, such non-trivial overlaps are usually excluded by genome annotation pipelines and, thus, only a few overlapping gene pairs have been described in bacteria. In contrast, transcriptome and translatome sequencing reveals many signals originated from the antisense strand of annotated genes, of which we analyzed an example gene pair in more detail.

Results: A small open reading frame of Escherichia coli O157:H7 strain Sakai (EHEC), designated laoB (L-arginine responsive overlapping gene), is embedded in reading frame -2 in the antisense strand of EC55115, encoding a CadC-like transcriptional regulator. This overlapping gene shows evidence of transcription and translation in Luria-Bertani (LB) and brain-heart infusion (BHI) medium based on RNA sequencing (RNAseq) and ribosomalfootprint sequencing (RIBOseq). The transcriptional start site is 289 base pairs (bp) upstream of the start codon and transcription termination is $155 \mathrm{bp}$ downstream of the stop codon. Overexpression of LaoB fused to an enhanced green fluorescent protein (EGFP) reporter was possible. The sequence upstream of the transcriptional start site displayed strong promoter activity under different conditions, whereas promoter activity was significantly decreased in the presence of L-arginine. A strand-specific translationally arrested mutant of laoB provided a significant growth advantage in competitive growth experiments in the presence of L-arginine compared to the wild type, which returned to wild type level after complementation of laoB in trans. A phylostratigraphic analysis indicated that the novel gene is restricted to the Escherichia/Shigella clade and might have originated recently by overprinting leading to the expression of part of the antisense strand of ECs5115.
\end{abstract}

Conclusions: Here, we present evidence of a novel small protein-coding gene laoB encoded in the antisense frame -2 of the annotated gene ECs5115. Clearly, laoB is evolutionarily young and it originated in the Escherichia/Shigella clade by overprinting, a process which may cause the de novo evolution of bacterial genes like laoB.

Keywords: Overlapping gene, Overprinting, Small protein, De novo gene, EHEC

\footnotetext{
* Correspondence: neuhaus@tum.de

${ }^{1}$ Chair for Microbial Ecology, Wissenschaftszentrum Weihenstephan,

Technische Universität München, Weihenstephaner Berg 3, 85354 Freising,

Germany

${ }^{4}$ Core Facility Microbiome/NGS, ZIEL - Institute for Food \& Health, Technische

Universität München, Weihenstephaner Berg 3, 85354 Freising, Germany

Full list of author information is available at the end of the article
} 


\section{Background}

The DNA triplet code is constructed such that the majority of amino acids (AA) can be encoded by more than one codon, leading to the so-called degeneration of the genetic code. Codon position three shows the highest degeneration (wobble position), whereas position one is only slightly degenerated and position two is not degenerated [1]. Thus, a DNA double strand contains six possible reading frames, each of which has the capacity to encode a protein and it is feasible that the sequences of two or more proteincoding genes overlap. Most generally, overlapping genes (OLGs) share at least one nucleotide between the coding regions of two genes. When the reading frame of the evolutionary older established gene (mother gene) is defined as frame +1 , a same-strand overlap in reading frames +2 or +3 relative to the annotated gene is possible. Samestrand OLGs originate from programmed ribosomal frameshift [2, 3] or programmed transcriptional realignment [4]. Additionally, a second gene can overlap the mother gene antisense in frames $-1,-2$ or -3 . It is under debate, which antisense frame is preferred for the occurrence of OLGs. In E. coli, most long antisense open reading frames (ORFs) are detected in frame -1 [5]. However, this finding might be caused by codon bias of the mother gene [6, 7]. Whereas Krakauer [1] predicted highest constraints on frame -2 , in E. coli more long ORF are found in frame -2 than in $-3[6,8]$. Lèbre and Gascuel [9] investigated the constraints of OLGs at the AA level and detected the highest constraints on frame -3 due to a high number of "forbidden dipeptides" within the protein encoded, which would cause a stop codon in the established gene.

In prokaryotes, many genes are organized in operons, which are transcribed as a polycistronic mRNA. In these cases, trivial same-strand overlaps of only a few base pairs are very common and facilitate translational coupling [10]. In contrast, almost no long OLGs (overlap $\geq 90 \mathrm{bp}$ ) have been described in bacteria [11-14], while longer OLGs are well known in viral genomes, probably leading to genome size reduction, since in viruses, $38 \%$ of all AA are encoded overlapping and in many cases the OLGs encode accessory proteins with unusual sequence composition like many disordered regions [15-17].

OLGs may originate by overprinting [18]: By chance, an overlapping reading frame is expressed in a bacterial population. However, encoding two functional genes at one locus leads to severe constraints of sequence evolution, since many mutations will influence the AA sequence of two genes carrying completely different functions $[1,8,9]$. This may be one reason why the overprinting hypothesis has been neglected as being rather unlikely [7, 19]. Instead, the gene duplication followed by subfunctionalization or neofunctionalization hypothesis [20] has been favored for the origin of novel genes.

Here, we present an initial functional characterization of the novel OLG $l a o B$ of EHEC, the expression of which was seen in transcriptome data and ribosomal profiling [21]. laoB overlaps antiparallel to the annotated gene ECs5115, and this overlapping gene pair is a novel example of this seemingly rare form of bacterial gene organization. We propose that $l a o B$ originated very recently by overprinting.

\section{Methods}

Bacterial strains and plasmids used in this study are listed in Additional file 1. Oligonucleotides are listed in Additional file 2.

\section{Determination of transcriptional start site by $\mathbf{5}^{\prime}$ rapid amplification of copy-DNA ends (RACE)}

An overnight culture of Escherichia coli O157:H7 strain Sakai (GenBank accession NC_002695, EHEC) [22] was inoculated $1: 100$ in $0.5 \times \mathrm{LB}$ with $400 \mathrm{mM} \mathrm{NaCl}$ and incubated at $37{ }^{\circ} \mathrm{C}$ and $150 \mathrm{rpm}$ until an $\mathrm{OD}_{600}$ of 0.8 was reached. Total RNA of $500 \mu \mathrm{l}$ EHEC culture was isolated with Trizol and the remaining DNA was digested using $2 \mathrm{U} \mathrm{TURBO}^{\mathrm{Tm}}$ DNase (Thermo Fisher Scientific). The 5'RACE System for Rapid Amplification of cDNA Ends, Version 2.0 (Invitrogen) was used according to the manual. After the second polymerase chain reaction (PCR), the dominant product was excised from the agarose gel and purified with the GenElute ${ }^{\mathrm{Tm}}$ Gel Extraction Kit (Sigma-Aldrich). The PCR product was Sanger sequenced by Eurofins with oligonucleotide $l a o B+25 R$.

\section{Determination of transcriptional stop site by 3'RACE}

Total RNA of $500 \mu \mathrm{l}$ EHEC overnight culture in LB medium was isolated using Trizol and the remaining DNA was digested using $2 \mathrm{U} \mathrm{TURBO}^{\text {TM }}$ DNase (Thermo Fisher Scientific). The 5'/3' RACE Kit, 2nd Generation (Roche Applied Science) was applied according to the manual, but instead of an oligo-dT primer for cDNA synthesis the gene specific primer laoB-12F was used. A nested PCR was performed for product amplification. The dominant product was excised from the agarose gel, purified with the GenElute ${ }^{\mathrm{Tm}}$ Gel Extraction Kit (SigmaAldrich) and Sanger sequenced (Eurofins) with oligonucleotide $l a o B+31 \mathrm{~F}$.

\section{Cloning of pProbe-NT plasmids and determination of promoter activity}

The genomic region $300 \mathrm{bp}$ upstream of the transcriptional start site was amplified by PCR and restriction enzyme cut sites for SalI and EcoRI were introduced. The PCR products were cloned into the plasmid pProbe-NT [23] and transformed into Escherichia coli Top10. The 
plasmid sequence was verified by Sanger sequencing (Eurofins). Overnight cultures of E. coli Top10+ pProbe-NT (negative control) and pProbe-NTPromoterTSS were used for 1:100 inoculation of $10 \mathrm{ml} 0.5 \times \mathrm{LB}$ medium with $30 \mu \mathrm{g} / \mathrm{ml}$ kanamycin. The following conditions were investigated for promoter activity in $0.5 \times \mathrm{LB}$ medium each: plain LB, at $\mathrm{pH} \mathrm{5}$, at $\mathrm{pH} 8.2$, plus $400 \mathrm{mM} \mathrm{NaCl}$, plus $0.5 \mathrm{mM}$ $\mathrm{CuCl}_{2}$, plus $2 \mathrm{mM}$ formic acid, plus $2.5 \mathrm{mM}$ malonic acid, or plus $10 \mathrm{mM} \mathrm{L}$-arginine. Cultures were incubated at $37{ }^{\circ} \mathrm{C}$ and $150 \mathrm{rpm}$ until an $\mathrm{OD}_{600}$ of 0.5 was reached. Then, the cells were pelleted, washed once with phosphate-buffered saline (PBS) and resuspended in $1 \mathrm{ml}$ PBS. The $\mathrm{OD}_{600}$ was adjusted to 0.3 and 0.6. Four-times each $200 \mu \mathrm{l}$ of both OD-adjusted suspensions were pipetted in a black microtiter plate and the fluorescence was measured (Wallac Victor ${ }^{3}$, Perkin Elmer Life Science, excitation $485 \mathrm{~nm}$, emission $535 \mathrm{~nm}$, measuring time $1 \mathrm{~s}$ ). The fluorescence of E. coli Top10 without vector was subtracted as background. To measure promoter activity after Larginine supplementation, the experiment was repeated in depleted modified Bacillus-growth (MOD) medium [24] without L-glutamic acid, L-arginine, and L-aspartic acid, since these AA are easily convertible within the cell. Depleted MOD medium and depleted MOD medium supplemented with $10 \mathrm{mM}$ L-arginine were tested. The experiments were performed in triplicate. Significance of changes was calculated by the two-tailed Student's t-test.

\section{Cloning of a C-terminal LaoB-EGFP fusion protein and overexpression of LaoB-EGFP protein}

The $l a o B$ sequence without the stop codon was amplified by PCR and restriction enzyme cut sites for PstI and NcoI were introduced. The PCR product was cloned into the plasmid pEGFP and transformed into Escherichia coli Top10. The plasmid sequence was verified by Sanger sequencing (Eurofins). For overexpression of the fusion protein, overnight cultures of E. coli Top $10+$ pEGFP and E. coli Top $10+$ pEGFP-laoB were inoculated 1:100 in $10 \mathrm{ml} 0.5 \times \mathrm{LB}$ medium with $120 \mu \mathrm{g} / \mathrm{ml}$ ampicillin in duplicates. Cultures were incubated at $37{ }^{\circ} \mathrm{C}$ and $150 \mathrm{rpm}$ until an $\mathrm{OD}_{600}$ of 0.3 was reached. For one culture each, protein expression was induced using $10 \mathrm{mM}$ isopropyl$\beta$-D-1-thiogalactopyranoside (IPTG). Incubation of induced and uninduced cultures was continued for $1 \mathrm{~h}$. Cells were pelleted, washed once with PBS and the pellet was resuspended in $1 \mathrm{ml}$ PBS. The $\mathrm{OD}_{600}$ was adjusted to 0.3 and 0.6. Four times each $200 \mu \mathrm{l}$ of the ODadjusted bacterial suspensions were pipetted in a black microtiter plate and the fluorescence was measured as before. The experiment was performed in triplicate.
Significance of changes was calculated by the two-tailed Student's t-test.

\section{Cloning of a translationally arrested laoB mutant}

For cloning of the genomic knock-out mutant $\triangle l a o B$, the method described by Kim et al. [25] was adapted. The mutations introduced do not change the AA sequence of the overlapping gene ECs5115. The $\mathrm{pHA}_{1887}$ fragment and the selection cassette were amplified by PCR from the plasmid pTS2Cb. Three consecutive point mutations, leading to a premature stop codon (5th codon) and a restriction enzyme cut site deletion (see below), were introduced into the $l a o B$ sequence by PCR using the oligonucleotides HA3laoB-139F and SM5laoBmut $+42 \mathrm{R}$ ( $3^{\prime}$ mutation fragment) and SM3laoBmut-16F and HA5laoB+183R (5' mutation fragment). Because the plasmid pTS2Cb- $\Delta l a o B$ was obtained by Gibson Assembly, the four PCR fragments contain overlapping sequences. In a total reaction volume of $20 \mu \mathrm{l}, 200 \mathrm{fmol}$ of each PCR fragment and the NEBuilder ${ }^{\circ} \mathrm{HiFi}$ DNA Assembly Master Mix (NEB) were incubated at $50{ }^{\circ} \mathrm{C}$ for $4 \mathrm{~h}$. Two $\mu \mathrm{l}$ of the reaction were transformed into $E$. coli Top10 and plated on LB agar with $120 \mu \mathrm{g} / \mathrm{ml}$ ampicillin and $20 \mu \mathrm{g} / \mathrm{ml}$ chloramphenicol. Next, the mutation cassette was amplified by PCR using pTS2Cb- $\triangle l a o B$ as template and the PCR product of correct size was purified from an agarose gel (GenElute ${ }^{\text {Tx }}$ Gel Extraction Kit; Sigma-Aldrich). EHEC [22] was transformed with the plasmid pSLTS and, subsequently, transformed with $75 \mathrm{ng}$ of the mutation cassette. After incubation for $3 \mathrm{~h}$ at $30{ }^{\circ} \mathrm{C}$ and $150 \mathrm{rpm}$ in SOC medium, the cells were plated on LB-agar plates with $120 \mu \mathrm{g} / \mathrm{ml}$ ampicillin and $20 \mu \mathrm{g} / \mathrm{ml}$ chloramphenicol and incubated at $30{ }^{\circ} \mathrm{C}$. One colony per plate was suspended in PBS. One-hundred $\mu \mathrm{l}$ of a 1:10 dilution in PBS were plated on LB agar with $120 \mu \mathrm{g} / \mathrm{ml}$ ampicillin and $100 \mathrm{ng} / \mathrm{ml}$ anhydrotetracycline for I-SceI induction and incubated at $30{ }^{\circ} \mathrm{C}$ over night. Several colonies were streaked on LB agar with $20 \mu \mathrm{g} / \mathrm{ml}$ chloramphenicol and plain LB agar and incubated at $37{ }^{\circ} \mathrm{C}$ over night. Colonies that were only able to grow on LB were selected and the genomic area surrounding the point mutations introduced was amplified by PCR. Additional to the premature stop codon, the restriction enzyme cut site for MnlI was deleted, which was screened for by restriction digest of PCR products with this enzyme. Correct introduction of the three point mutations was assumed for MnlI-digestion negative PCR products and confirmed by Sanger sequencing (Eurofins).

\section{Competitive growth assays}

Overnight cultures in LB medium of EHEC wild type and EHEC $\triangle l a o B$ were adjusted to an $\mathrm{OD}_{600}$ of 1.0 and then mixed in equal quantities $(500 \mu \mathrm{l}$ wild type $+500 \mu \mathrm{l}$ 
mutant). Five-hundred $\mu \mathrm{l}$ of the mixture were pelleted and the cells were snap frozen in liquid nitrogen (control, $\mathrm{t}=0$ ). Ten $\mathrm{ml} 0.5 \times \mathrm{LB}$ medium were inoculated 1:3000 with the mixed EHEC culture. The following conditions were investigated in $0.5 \times \mathrm{LB}$ : plain LB, at $\mathrm{pH} 5$, at $\mathrm{pH} 8.2$, plus $400 \mathrm{mM} \mathrm{NaCl}$, plus $0.5 \mathrm{mM} \mathrm{CuCl}_{2}$, plus $2 \mathrm{mM}$ formic acid, plus $2.5 \mathrm{mM}$ malonic acid, plus $4 \mathrm{mM}$ malic acid, plus $400 \mu \mathrm{M} \mathrm{ZnCl}_{2}$, or plus $20 \mathrm{mM} \mathrm{L-}$ arginine. Cultures were incubated for $18 \mathrm{~h}$ at $37^{\circ} \mathrm{C}$ and $150 \mathrm{rpm}$. Then, $500 \mu \mathrm{l}$ of the culture were pelleted, $100 \mu \mathrm{l}$ water were added to the pellet and the sample was heated to $95{ }^{\circ} \mathrm{C}$ for $10 \mathrm{~min}$. Using this crude DNA preparation, a PCR was performed with the primer pair $l a o B-38 \mathrm{~F}$ and $l a o B+140 \mathrm{R}$. The PCR product was Sanger sequenced (Eurofins) and the ratio between wild type and mutant $\triangle l a o B$ was determined by comparing peak heights. The absolute numbers were transformed into percentage values for each condition and the values were normalized to a $t=0$ ratio for 50:50 wild type over $\mathrm{mu}$ tant. Thus, the competitive index (CI) was calculated using the following formula:

$$
C I=\frac{\text { mutant }_{\text {end }}[\%] \times \text { wild type }_{\text {start }}[\%]}{\text { mutant }_{\text {start }}[\%] \times \text { wild type }_{\text {end }}[\%]}
$$

The experiment was performed in biological triplicates. Significance was calculated by the two-tailed Student's t-test.

\section{Complementation of EHEC $\triangle / a O B$}

To compensate the $l a o B$ genomic knockout mutation, the intact $l a o B$ ORF was supplemented in trans on a plasmid. First, the sequence of $l a o B$ was amplified by PCR and restriction enzyme cut sites for NcoI and Hin$d$ III were introduced. The PCR product was cloned into the plasmid $\mathrm{pBAD} / \mathrm{Myc}-\mathrm{His}-\mathrm{C}$ and the plasmid was transformed into EHEC $\triangle l a o B$. As a negative control, the plasmid containing the mutated $l a o B$ gene $(\Delta l a o B)$ was cloned. Next, competitive growth experiments were performed as described above using EHEC $\triangle l a o B+$ pBAD-laoB (complementation) and EHEC $\triangle l a o B+$ pBAD- $\triangle$ lao $B$ (control). Both overnight cultures were supplemented with $120 \mu \mathrm{g} / \mathrm{ml}$ ampicillin and the cultures were mixed in equal ratio. Ten $\mathrm{ml}$ of either $0.5 \times$ $\mathrm{LB}$ or $0.5 \times \mathrm{LB}+20 \mathrm{mM} \mathrm{L}$-arginine were inoculated 1:3000 in quadruplicates. Induction of the $l a o B$ frame (present either as wild type or as $\triangle l a o B$ ) was performed with $0.002 \%$ arabinose. After incubation at $37{ }^{\circ} \mathrm{C}$ and 150 rounds per minute (rpm) for $18 \mathrm{~h}$, plasmids were isolated using the GenElute ${ }^{\mathrm{mm}}$ Plasmid Miniprep Kit (Sigma-Aldrich). Using $20 \mathrm{ng}$ isolated plasmid, PCR was performed with the oligonucleotides $\mathrm{pBAD}+208 \mathrm{~F}$ and $\mathrm{pBAD}+502 \mathrm{R}$. The PCR products were Sanger sequenced (Eurofins) and the ratio of intact laoB over translationally arrested $\triangle l a o B$ was determined in percent. The experiment was performed in biological triplicates. Significant changes were calculated by the two-tailed Student's t-test.

\section{Transcriptome and translatome sequencing}

RNAseq and RIBOseq data sets of Hücker et al. [26] were investigated with respect to translated ORFs located in antisense to annotated genes. Briefly, the bacteria had been grown under the following growth conditions: $\mathrm{LB}$ medium at $37{ }^{\circ} \mathrm{C}$, harvested at $\mathrm{OD}_{600} 0.4$, $\mathrm{BHI}$ medium at $37^{\circ} \mathrm{C}$, harvested at $\mathrm{OD}_{600} 0.1$, and $\mathrm{BHI}$ medium supplemented with $4 \% \mathrm{NaCl}$ at $14{ }^{\circ} \mathrm{C}$, harvested at $\mathrm{OD}_{600}$ 0.1. An ORF was considered translated, when (i) it was covered with at least one read per million mapped sequenced reads normalized to $1 \mathrm{kbp}$, (ii) $\geq 50 \%$ of the ORF is covered with RIBOseq reads, and (iii) the ribosomal coverage value (RCV) is at least 0.25 in both biological replicates. All three requirements were matching for $l a o B$, which was verified by visual inspection using the Artemis genome browser [27].

\section{Bioinformatics methods to characterize $I a O B$ Prediction of $\sigma^{70}$ promoters}

The region 550 bp upstream of the start codon of $l a o B$ was searched for the presence of a $\sigma^{70}$ promoter with the program BPROM (Softberry) [28]. The linear discriminant functions (LDF) score given is a measure of promoter strength, whereupon an LDF score of 0.2 indicates presence of a $\sigma^{70}$ promoter with $80 \%$ accuracy and specificity.

\section{Prediction of alternative $\sigma$-factors}

The search for alternative $\sigma$-factors was performed manually. The sequence 50 bp upstream of the detected transcription start site (TSS) was compared to the consensus motifs of $\sigma^{28}$ [29], $\sigma^{32}$ [30], and $\sigma^{54}$ [31].

\section{Prediction of $\rho$-independent terminators}

The region $300 \mathrm{bp}$ downstream of the stop codon of $l a o B$ was searched for the presence and folding energy of a $\rho$-independent terminator using the program FindTerm (Softberry) [28].

\section{Prediction of Shine-Dalgarno (SD) sequence}

The free energy $\Delta G^{\circ}$ of the region $30 \mathrm{bp}$ upstream of the start codon of $l a o B$ was calculated according to Ma et al. [32]. The perfect SD sequence taAGGAGGt has a $\Delta G^{\circ}$ of -9.6. A $\Delta G^{\circ}$ of -2.9 is considered the threshold for the presence of an SD sequence [32]. 


\section{Detection of annotated homologs}

The AA sequence LaoB, corresponding to $l a o B$, was used to query the data base GenBank with blastp using default parameters [33].

\section{PredictProtein}

LaoB was submitted to the software PredictProtein [34]. The methods PROFphd (secondary structure) [35], TMSEG (transmembrane helices) [36], DISULFIND (disulfide bonds) [37] and LocTree2 (subcellular localization) [38] were used.

\section{Phylogenetic tree construction}

For evolutionary analysis of $l a o B$ and ECs5115, tblastn was used with an e-value cutoff of 0.001 and at least $50 \%$ identity, which allows a search of nucleotide sequences homologous to a protein sequence query in all genomic sequences of the database independent of their annotation status $[39,40]$. For the short gene of LaoB, tblastn was not sensitive enough to detect all existing genomic sequences; hence, hits matching ECs5115 were used for subsequent laoB analysis. Continuous laoB ORFs were detected in a total of 497 Escherichia and 18 Shigella strains (see results). However, a large number of genes had the very same laoB sequence. Thus, examples of 11 LaoB-encoding sequences, representing the diversity of continuous laoB genes, were chosen. Likewise, exemplary ECs5115 sequences within a broad range of different sequence identities were downloaded from the database and used for phylogenetic analysis. Multiple sequence alignments of ECs5115 and LaoB homologs were conducted using MUSCLE implemented in MEGA6 [41]. The automated alignments were manually checked and adapted, where necessary. Parts encoding sequences homologs to LaoB were manually identified in -2 frame of ECs5115. Those sequences with no obvious similarity to $l a o B$ were identified by pairwise alignments of the nucleotide sequence of the -2 frame of the respective ECs5115 homolog (EMBOSS Needle, [42]). The area which aligned to $l a o B$ was translated to its AA sequence and further aligned outside the initial region by multiple sequence alignments, as before. The $l a o B$ sequence was only found to be discontinuous outside the Escherichia/ Shigella clade. Thus, indel-like sequence insertions and internal stop codons are present in sequences of bacteria outside Escherichia/Shigella, encoding peptide fragments shorter than $41 \mathrm{AA}$ or AA sequences which are very different from LaoB.

Reference phylogenetic trees of the strains and species examined were constructed according to Fellner et al. [14]. Briefly, a concatenated sequence of the housekeeping genes $16 \mathrm{~S}$ rDNA, atpD, adk, gyrB, purA and $\operatorname{rec} A$ was used. The sequences were aligned using ClustalW in MEGA6. Columns with gaps or ambiguities were removed. The final dataset contains 7484 positions. The best nucleotide substitution model was searched for using MEGA6. The final Maximum-Likelihood tree was calculated using Neighbor Joining and bootstrapped 1000 times. The best nucleotide substitution model for tree construction was identified to be the General Time reversible model (GTR with a lowest Bayesian Information Criterion of 123,336.358). The non-uniformity of evolutionary rates among substitution sites was modeled using a discrete Gamma distribution with five rate categories $(+\mathrm{G}$, parameter $=0.5494)$. The log likelihood value of the final tree was $-61,963.20$.

\section{Results}

Detection of a transcribed and translated antiparallel overlapping ORF

Combined RNAseq and RIBOseq data of EHEC grown at three different growth conditions were searched for ORFs, which are antiparallel overlapping to annotated genes and show signals for transcription and translation. Further, the translatability of the ORFs was calculated using the RCV, which is defined as the quotient of reads per kilobase per million mapped reads (RPKM) of the translatome over transcriptome RPKM [43]. The annotated ECs5115 (1539 bp) encodes a transcriptional regulator of the CadC family and shows signals for transcription (RNAseq) and translation (RIBOseq) on the sense and antisense strand (Fig. 1). The latter reads correspond to a small ORF completely embedded within ECs5115 in the reading frame -2 relative to ECs5115, encoding a short hypothetical protein of $41 \mathrm{AA}$. A blastp search for annotated homologs resulted in a single hit to a hypothetical protein of Escherichia albertii TW07627 (GenBank accession EDS93387.1) with an e-value of $5 \times$ $10^{-13}$ and $78 \%$ identity. The software PredictProtein could not detect transmembrane helices or disulfide bonds and the hypothetical protein is predicted to be secreted. The strongest transcription of the ORF was found in BHI medium at $37{ }^{\circ} \mathrm{C}$ (Table 1A), whereas translation (RPKM) and translatability (RCV) are highest in LB at $37^{\circ} \mathrm{C}$. ECs5115 is only weakly transcribed and read numbers decrease over the length of the gene (Fig. 1 and Table 1B). Translation of both reading frames, ECs5115 and laoB is almost completely switched off at combined cold and osmotic stress.

\section{Characterization of $I a O B$ promoter region}

A predicted SD sequence $\left(\Delta G^{\circ}\right.$ of -6.8$)$ is present $15 \mathrm{bp}$ upstream of the putative start codon (Fig. 2c). A single transcriptional start site was identified 289 bp upstream of the start codon by 5 'RACE. This would imply a very long $5^{\prime}$ untranslated region (UTR). Therefore, the region was searched for additional ORFs. Indeed, another ORF $(\operatorname{la} o A)$, which would encode a protein of $61 \mathrm{AA}$, is 


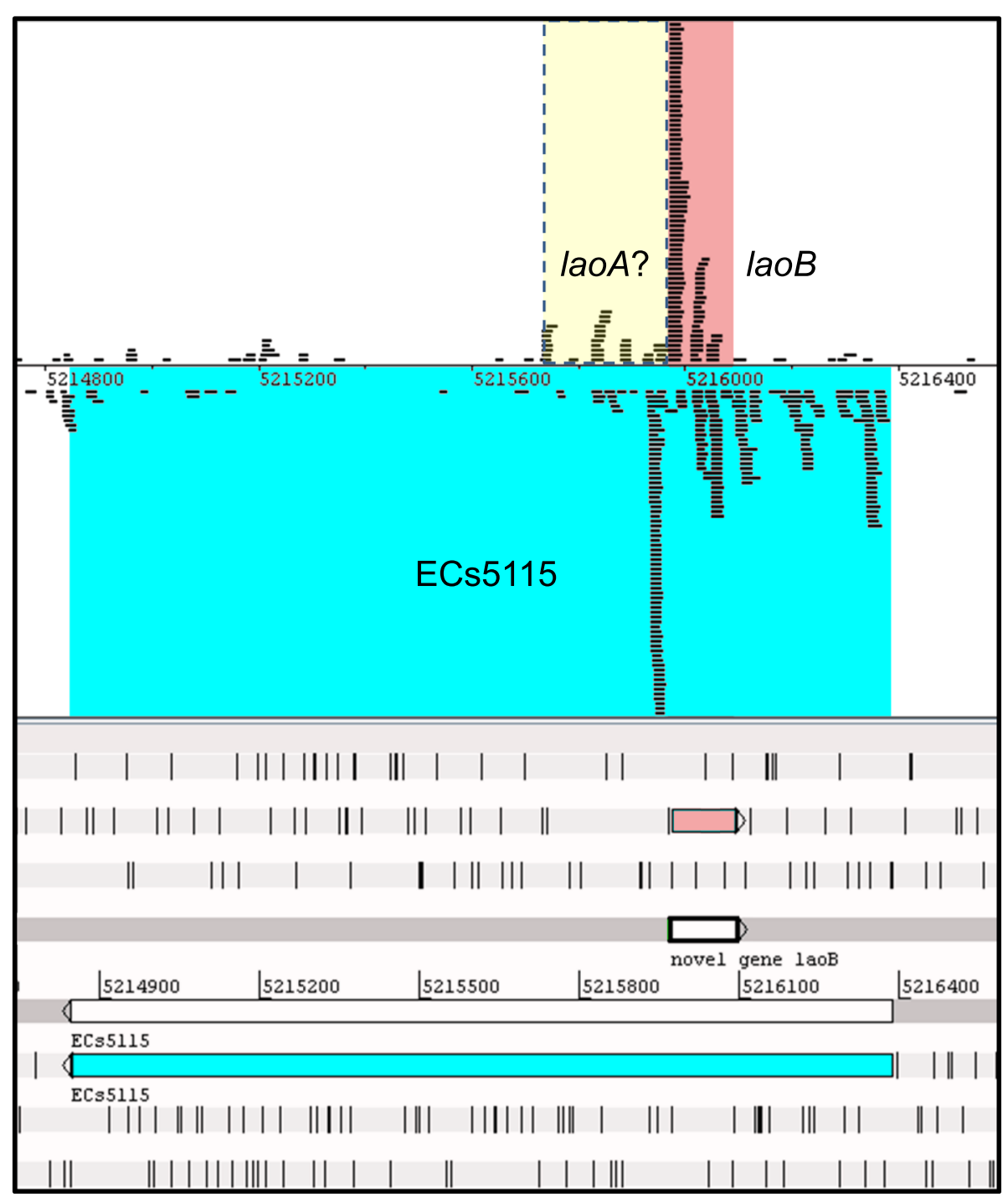

Fig. 1 Translation of laoB in LB medium. RIBOseq reads mapped strand-specifically to the overlapping gene pair laoB/ECs5115 are visualized in Artemis. The annotated gene ECs5115 is highlighted in blue. The novel gene laoB is highlighted in pink. A potential, non-characterized overlapping gene laoA is highlighted in yellow

located directly upstream of the OLG laoB (Fig. 2a). However, this ORF is only weakly translated (Fig. 1 and Table 1C). Furthermore, it does not have annotated homologs, and in its upstream region, no SD sequence was detected. Thus, this ORF was not characterized further. While FindTerm does not predict a $\rho$-independent terminator in the region $300 \mathrm{bp}$ downstream of the stop codon, a transcriptional stop site was determined $155 \mathrm{bp}$ downstream of the stop codon by 3'RACE (Fig. 2c).

The software BPROM did not predict a $\sigma^{70}$ promoter in the upstream region of $l a o B$ in a suitable distance to the TSS. Therefore, the region upstream of the TSS was manually investigated for the presence of alternative $\sigma$ factor consensus motifs. Interestingly, a sequence with high similarity to the $\sigma^{32}$ consensus motif was detected in proper distance to the TSS (Fig. 2b). The sequence $300 \mathrm{bp}$ upstream of the TSS, containing the potential $\sigma^{32}$ promoter, was cloned into pProbe-NT for investigation of promoter activity at different growth conditions. Significant promoter activity was detectable at all conditions tested (Fig. 3a). LB supplemented with $400 \mathrm{mM} \mathrm{NaCl}$ lead to the highest fluorescence intensity with a 2.9-fold increase compared to LB. Additionally, the conditions $\mathrm{LB}+2.5 \mathrm{mM}$ malonic acid and LB at pH 5 showed a significantly increased promoter activity. Promoter activity was reduced in LB supplemented with $10 \mathrm{mM} \mathrm{L}$-arginine of about 1.3-fold. However, LB medium already contains Larginine. Therefore, the experiment was repeated in depleted MOD medium without $\mathrm{L}$-arginine and the 
Table 1 Transcription and translation of $l a o B$ (part 1A) and its mother gene ECs5115 (part 1B) at the three different growth conditions indicated. The RPKM values of the transcriptome (RNAseq) and the translatome (RIBOseq) data for the overlapping novel gene and annotated mother gene are listed, including the RCV, indicating their translatability. ORF coverage is the fraction of a gene sequence, which is covered by RIBOseq reads. In addition, the corresponding data for the putative overlapping gene laoA (compare Fig. 2a) are shown (part 1C)

\begin{tabular}{|c|c|c|c|c|}
\hline Condition & RPKM transcriptome ${ }^{a}$ & RPKM translatome ${ }^{a}$ & $\mathrm{RCV}^{\mathrm{a}}$ & ORF coverage $^{a}$ \\
\hline \multicolumn{5}{|l|}{$1 \mathrm{~A} / a O B$} \\
\hline $\mathrm{LB}, 37^{\circ} \mathrm{C}$ & 29.5 & 194 & 6.83 & 0.7 \\
\hline $\mathrm{BHI}, 37^{\circ} \mathrm{C}$ & 49.4 & 23.6 & 0.48 & 0.6 \\
\hline $\mathrm{BHI}+4 \% \mathrm{NaCl}, 14{ }^{\circ} \mathrm{C}$ & 28.3 & 0.2 & 0.01 & 0.07 \\
\hline \multicolumn{5}{|l|}{ 1B ECs5115 } \\
\hline $\mathrm{LB}, 37^{\circ} \mathrm{C}$ & 19 & 12.3 & 0.65 & 0.35 \\
\hline $\mathrm{BHI}, 37^{\circ} \mathrm{C}$ & 26.9 & 7.1 & 0.27 & 0.45 \\
\hline $\mathrm{BHI}+4 \% \mathrm{NaCl}, 14^{\circ} \mathrm{C}$ & 10.2 & 0.6 & 0.07 & 0.16 \\
\hline \multicolumn{5}{|l|}{ 1C laoA } \\
\hline $\mathrm{LB}, 37^{\circ} \mathrm{C}$ & 38.3 & 9.6 & 0.27 & 0.51 \\
\hline $\mathrm{BHI}, 37^{\circ} \mathrm{C}$ & 36.3 & 1.9 & 0.05 & 0.37 \\
\hline $\mathrm{BHI}+4 \% \mathrm{NaCl}, 14{ }^{\circ} \mathrm{C}$ & 12.7 & 0.4 & 0.02 & 0.16 \\
\hline
\end{tabular}

${ }^{a}$ Mean values of the two biological replicates are shown
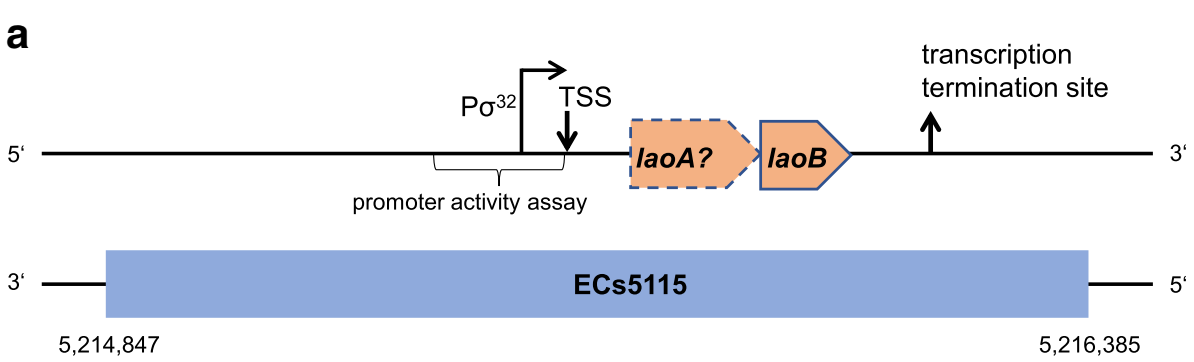

b

$$
\begin{aligned}
& \text { consensus } \sigma 32 \\
& \text { sequence upstream TSS lao } B
\end{aligned}
$$

CCCCATNT

CaCCATAa

C

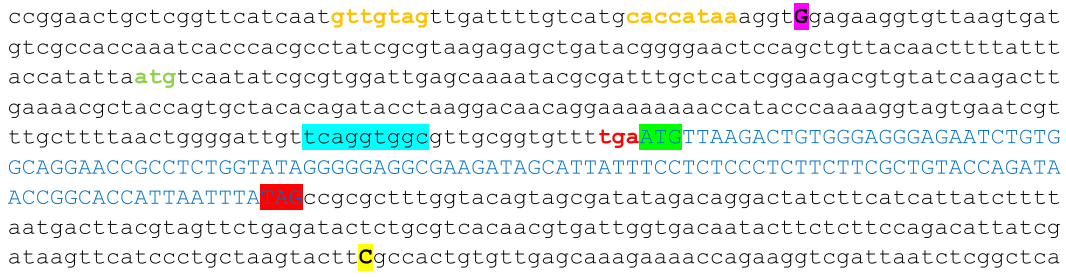

Fig. 2 The overlapping gene pair laoB/ECs5115 and the regions upstream and downstream. a Schematic view of the overlapping gene pair IaOAB/ECs5115. Positions of the promoter, TSS, and transcription termination are indicated (not to scale). $\mathbf{b}$ Alignment of the proposed $\sigma^{32}$ promoter to the consensus motif. c DNA sequence of the novel gene laoB and the upstream and downstream regions. The sequence of laoB is colored in blue and written in capital letters. The start codon is highlighted in green and the stop codon in red. Also the start and stop codon of the potential upstream gene laoA are marked (lower case, green and red, respectively). The TSS detected by $5^{\prime}$ RACE is highlighted in pink and the transcriptional stop determined by $3^{\prime} R A C E$ is highlighted in yellow. The putative $\sigma^{32}$ promoter is colored in orange. The SD sequence upstream laoB is highlighted in light blue 

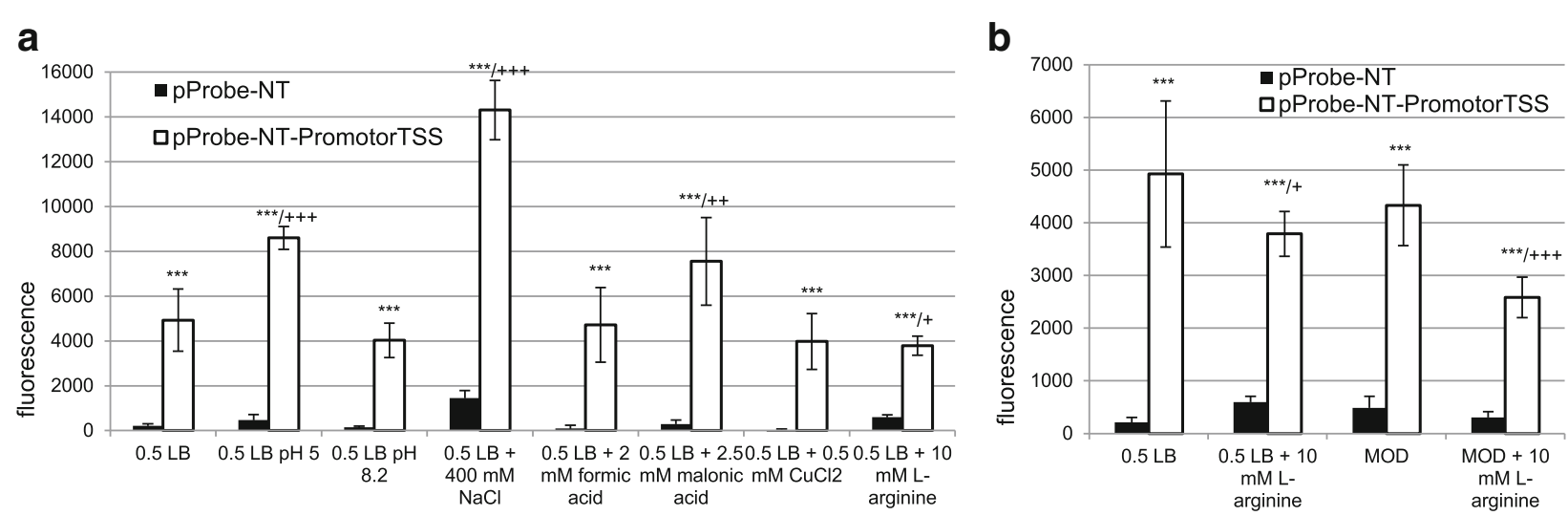

Fig. 3 Promoter activity of the region $300 \mathrm{bp}$ upstream of the laoB TSS. Significant changes between vector control and pProbe-NT-PromoterTSS are marked with asterisks (*** $p<0.001)$. Significant differences between $0.5 \times \mathrm{LB}$ and investigated stress conditions are marked with a plus $(+p<0.05,++$ $p<0.01,+++p<0.001)$. a Promoter activity of the region $300 \mathrm{bp}$ upstream of the determined TSS in LB medium with different supplementations. $\mathbf{b}$ Promoter activity of the region 300 bp upstream of the TSS in LB or depleted MOD medium and LB or in depleted MOD medium supplemented with $10 \mathrm{mM}$ L-arginine

convertible AA, which leads to a more pronounced decline of promoter activity (Fig. $3 \mathrm{~b}$ ).

\section{Expression of a LaoB-EGFP fusion protein}

Next, it was investigated whether the LaoB protein can be expressed in E. coli. For this purpose, the laoB sequence was cloned in-frame and upstream of EGFP, and transformed into $E$. coli Top10. After induction with IPTG, a fluorescent LaoB-EGFP fusion protein was produced. The induced culture shows an 11.7-fold increased fluorescence intensity compared to the uninduced culture demonstrating expression of the fusion protein (Fig. 4).

The translationally arrested mutant $\Delta / a O B$ shows a growth advantage in arginine-containing media

For functional characterization of $l a o B$ the knock-out mutant $\triangle l a o B$ was created using genome editing [25]. A premature stop codon at the fifth codon of $l a o B$ was generated by a point mutation (Fig. 5a). Two additional point mutations were introduced in adjacent nucleotides to delete an $\mathrm{MnII}$ restriction enzyme cut site (required for easier selection). The AA sequence of ECs5115 is not changed by the point mutations, because the affected codon of the mother gene still encodes serine.

To find a potential phenotype, competitive growth experiments with EHEC wild type and $\triangle l a o B$ were performed. The equal-ratio mixture of wild type and mutant was incubated under different conditions and a potential growth advantage was determined by the ratio of the wild type and mutant genes at the endpoint. When LB medium was supplemented with $20 \mathrm{mM} \mathrm{L-}$ arginine, a phenotype was detected: EHEC $\triangle l a o B$ displayed a significant growth advantage indicated by a ratio of wild type to mutant of 15:85 (Fig. 5b). Thus, the
$\mathrm{CI}$ is 13.6. No phenotype was found for any other conditions tested (Additional file 3).

Intact laoB, cloned into pBAD-myc-His-C, should restore the phenotype of EHEC wild type. Therefore, competitive growth experiments using EHEC $\triangle l a o B$ carrying pBAD-laoB against EHEC $\Delta l a o B+$ pBAD- $\Delta l a o B$ (mutant control) were performed. Expression of lao $B$ was induced with arabinose. As expected, in plain LB, the ratio between the two strains tested did not change independent whether the plasmid borne $l a o B$ was induced or not (Fig. 5c). In contrast, in LB supplemented with $20 \mathrm{mM}$ $\mathrm{L}$-arginine, the strain carrying the functional laoB-copy

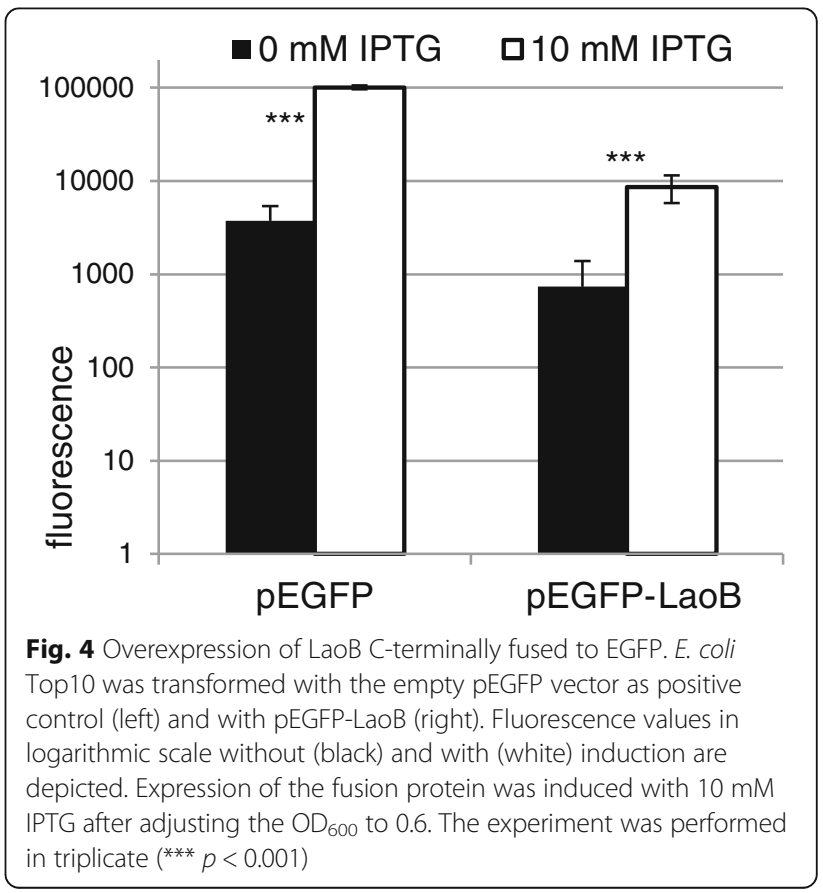



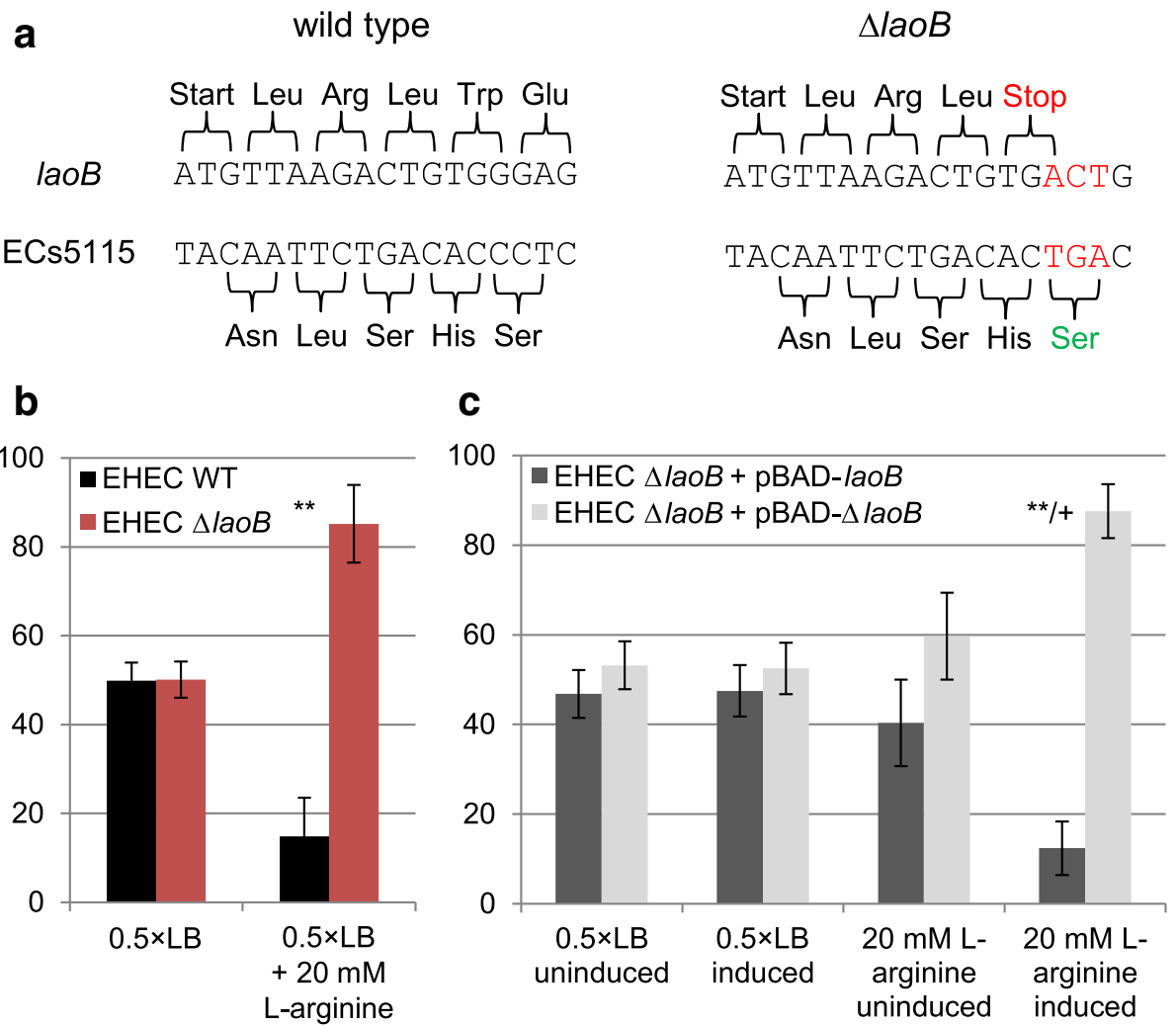

Fig. 5 Nucleotide sequence and phenotype of EHEC $\triangle \mathrm{AaO} B$. a Construction of a translationally arrested $\triangle l a O B$ mutant. Introduction of a point mutation in the DNA sequence of $1 a O B$ changed the fifth codon encoding glutamine to a premature stop codon. Because of two adjacent mutations, a cut site for the restriction enzyme $\mathrm{Mnll}$ is deleted at this position. The three point mutations do not influence the AA sequence of the antiparallel overlapping annotated gene ECs5115. b Ratio in percent of EHEC wild type to EHEC $\triangle$ laoB after competitive growth. Wild type and mutant were mixed in equal ratios and after $18 \mathrm{~h}$ incubation at different growth conditions, their ratio was determined. In $0.5 \times \mathrm{LB}$, no change compared to the inoculation ratio occurred, but when the medium was supplemented with $20 \mathrm{mM} \mathrm{L}$-arginine, EHEC $\triangle$ laoB shows a significant growth advantage. The experiment was performed in triplicate $\left.{ }^{* *} p<0.01\right)$. c Complementation of EHEC $\triangle / a O B$ using a plasmid-borne laoB. The diagram shows the ratios in percent of EHEC $\triangle / a O B+p B A D-l a o B$ and EHEC $\triangle / a O B+p B A D-\triangle l a O B$ after competitive growth. The experiment was performed in triplicate. Significant changes between uninduced and induced conditions are marked with a plus $(+p<0.05)$. Significant changes between $0.5 \times L B$ and $0.5 \times L B+20 \mathrm{mM} L$-arginine are marked with asterisks $\left({ }^{* *} p<0.01\right)$

shows a significant growth disadvantage if induced with arabinose. This reflects the competitive growth phenotype of the wild type strain compared to the mutant strain (Fig. 5b). Thus, translation arrested laoB can be complemented in trans.

\section{Phylostratigraphic analysis of $I a O B$}

Two tblastn searches with ECs5115 and $l a o B$ as queries were performed to determine the taxonomic distribution of both genes. A continuous laoB-encoding gene was detected only in Escherichia and Shigella strains (Fig. 6 and Additional file 4). The antiparallel overlapping, annotated ECs5115 has further homologs in many bacterial phyla outside Escherichia/Shigella (Additional file 5). However, in those sequences, the embedded laoB ORF is either quite different in the encoded AA sequence compared to the original $l a o B$ or composed of uncontinuous segments. Thus, either stop codons break the $l a o B$ frame or frame- shift-like modifications are causing observed differences. When a continuous $l a o B$ homolog is present, its sequence is always highly conserved, showing only a few AA substitutions, but neither premature stop codons nor frameshift mutations. The highest sequence variability in intact LaoB homologs occurs in E. fergusonii (Fig. 6).

\section{Discussion}

This study provides evidence for a novel overlapping gene pair, laoB/ECs5115, in EHEC. Transcription and translation of a short ORF, embedded in the antisense reading frame -2 to a CadC-like transcriptional regulator, was detected by RNAseq and RIBOseq at optimal growth conditions. Translational knockout of the ORF by a premature stop codon resulted in a significant growth advantage of the mutant strain in LB medium supplemented with L-arginine over the wild type strain in competitive growth. Consistently, the activity of the 

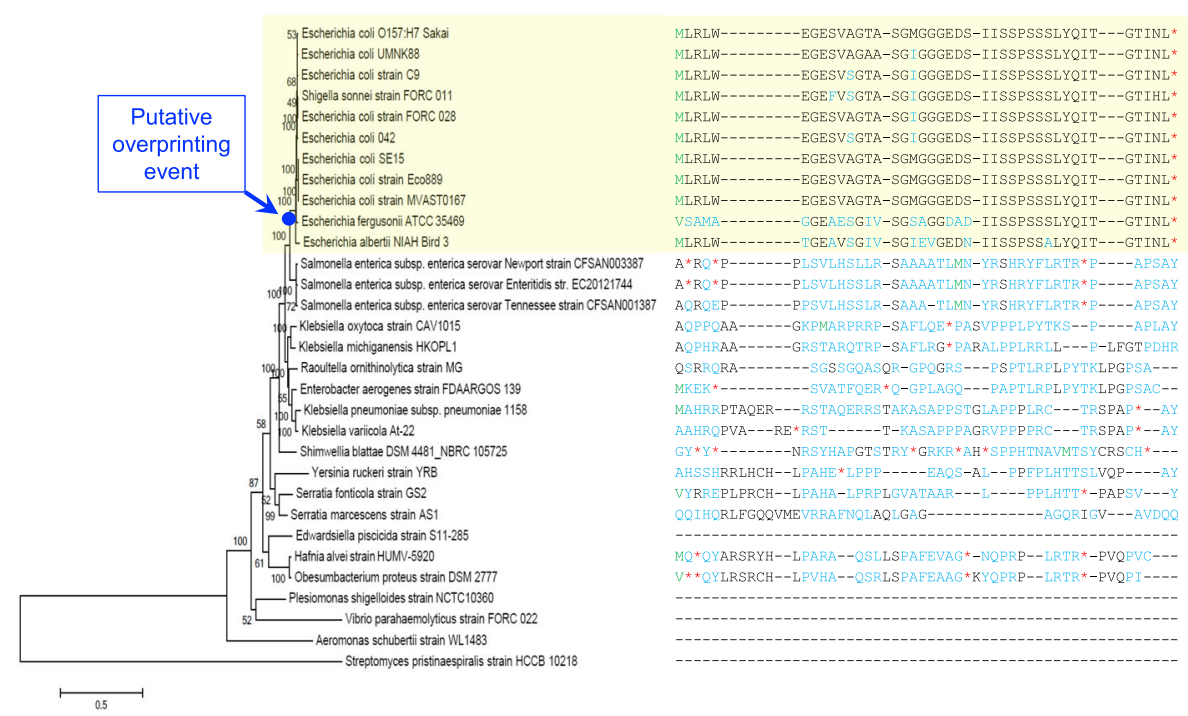

Fig. 6 Phylogenetic tree and alignment of laoB. The phylogenetic tree to the left was constructed based on a concatemer of 16S rDNA, atpD, $a d k$, gyrB, purA, and recA. To the right, the different AA sequences of LaoB are aligned. Start codons are colored in green, AA changes in blue, and stop codons $\left(^{*}\right)$ in red

putative $\sigma^{32}$ promoter is repressed by $\mathrm{L}$-arginine. Whether $l a O B$ is part of an overlapping operon together with $l a o A$, located upstream of $l a o B$, is unknown. LaoA was not examined, since transcription and translation of lao $A$ appeared to be very weak under the conditions tested.

\section{Is laoB a protein-coding gene?}

$L a o B$ might function as a novel non-coding RNA (ncRNA) instead of a novel protein-coding gene. However, due to the following reasons this appears to be unlikely: Most important, experimental data presented here confirm the protein-coding character of $l a o B$, since the ORF is covered by RIBOseq reads (Fig. 1). RIBOseq signals clearly indicate active translation of an RNA molecule $[44,45]$. In LB medium, the ORF has a very high RCV (Table 1A), which is much higher than the mean RCV of 1.55, which we found for short annotated EHEC genes $[26,43]$. In addition, stable translation into a protein was further confirmed by the expression of a LaoBEGFP fusion protein (Fig. 4). Second, a translationally arrested mutant lead to a clear phenotype which could be complemented by the wild type sequence in trans by using just the $l a o B$ ORF without any adjacent sequence attached (Fig. 5). If $l a o B$ would function as an antisense ncRNA, it would regulate its targets by base pairing with complementary mRNAs [46]. It appears to be unlikely that a translationally arrested mutant, which changes only $\sim 0.5 \%$ of the nucleotides compared to the complete transcript of the $l a o B$ sequence, would exert such a dramatic phenotype. Third, 15 bp upstream of the start codon an SD sequence is present (Fig. 2c). The distance of the SD to the start codon is within the natural ranges observed and the detected sequence is close to the SD consensus motif, resulting in strong ribosomal binding [32]. Finally, the laoB ORF has been annotated in $E$. albertii as a protein-coding gene.

\section{Putative function of LaoB}

The results presented in this work provide first hints towards a potential LaoB function. The region $300 \mathrm{bp}$ upstream of the TSS determined shows significant promoter activity at all investigated conditions (Fig. 3). The $l a o B$ promoter is probably recognized by the alternative $\sigma$-factor $\sigma^{32}$, since a sequence very similar to the $\sigma^{32}$ consensus motif is present in the proper distance to the TSS (Fig. 2b) [30]. The first $\mathrm{T}$ of the -35 box and the $\mathrm{A}$ of the -10 box are completely conserved in $\sigma^{32}$ promoters and both nucleotides are present in the $\sigma^{32}$ promoter region of $l a o B$. Additionally, the spacer between the -35 and -10 box has the optimal distance of $14 \mathrm{bp}$ and $\sigma^{32}$ promoters with this spacer distance tolerate a substitution of the second $\mathrm{C}$ of the tetra- $\mathrm{C}$ motif of the -10 box without losing promoter strength [47], which is also the case here. In addition, the distance between the -10 box and the TSS is in the optimal range of $6 \mathrm{bp}$ [30]. Transcription of heat shock genes is induced by $\sigma^{32}$. Accordingly, transcription of $l a o B$ is almost switched off at cold stress (Table 1A). The $\sigma^{32}$ stress regulon includes chaperons, transcription factors, DNA/RNA surveillance proteins, and many membraneassociated proteins [30]. In this study, the promoter has the highest activity in LB supplemented with $\mathrm{NaCl}$ and at acidic conditions (Fig. 3). Interestingly, $\sigma^{32}$ is also the 
master regulator of the transcription factor PhoPQ, which is also induced at acid stress [30].

In our hands, EHEC $\triangle l a o B$ only showed a clear phenotype after supplementing the medium with Larginine (Fig. 5b). As a proteinogenic AA, L-arginine is involved in many central metabolic pathways. Bacteria synthesize L-arginine from glutamate [48] or take it up from the environment by three different transporters [49]. Arginine can be utilized as sole carbon and nitrogen source and is the substrate for the synthesis of polyamines [48]. Here, high L-arginine concentrations resulted in a significantly reduced activity of the $l a o B$ promoter and the EHEC wild type has a clear growth disadvantage in competitive growth. These observations would agree with the speculation that LaoB might be involved in enhancing L-arginine uptake. In many EHEC reservoirs, nutrient concentrations, including L-arginine concentrations, are low and efficient uptake represents an advantage. The high arginine concentrations used in this study are unlikely to occur naturally. Therefore, under environmental conditions, which are low in arginine, intact LaoB may confer a growth advantage. The hypothesis that LaoB somehow interacts with arginine transport is supported by the facts that a high proportion of small proteins - LaoB has a size of only $41 \mathrm{AA}$ associates with the cell membrane, in which transporters are located $[50,51]$, and that the $\sigma^{32}$ regulon includes many membrane proteins [30]. However, testing this speculation and further functional characterization of LaoB must await future studies.

\section{Origin of $l a O B$ by overprinting}

The time of origin of an OLG can be estimated by phylostratigraphic analysis, comparing the phylogenetic distribution of the mother gene and the overlapping gene $[18,52]$. The intact laoB ORF is only present in Escherichia and Shigella strains (Fig. 6) while the annotated gene ECs5115 has a much broader taxonomical distribution (i.e., higher conservation level) and is present in both Gram-negative and Gram-positive bacteria (Additional file 5). It is concluded that $l a o B$ originated recently and might be an interesting example of de novo gene birth by overprinting $[18,52,53]$. This would mean that a number of point mutations in the ECs5115 sequence would have created the laoB ORF including its regulatory sequences after the Escherichia/Shigella clade separated from Salmonella. One may postulate that a weak $\sigma^{32}$ promoter sequence was already present at the proper location by chance and, later, may have been further optimized by additional point mutations leading to an increased transcription of the novel ORF. The resulting (m)RNA must have been used as template for translation, perhaps based on a weak ribosomal binding site which happened to be present upstream of the start codon. Now, one must assume that the AA chain, at this point, was functional ab initio by chance, conferring a fitness advantage to the cell. At this early evolutionary stage, a novel gene is volatile and the process is reversible, such that the novel ORF can get lost again [54]. A fitness gain related to the L-arginine metabolism may have led to fixation of the functional allele in the population by Darwinian evolution. Because EHEC colonizes many hosts and environments [55], which requires expression of different sets of genes [56, 57], LaoB might improve its fitness in one of those species specific niches. Alternatively, the novel ORF could have been fixed by neutral evolution together with the mutated mother gene [58]. Later on, extension at the $3^{\prime}$ end by the loss of a stop codon may occur, leading to an elongation of the novel protein which would be more likely than $5^{\prime}$ elongation due to regulatory elements in the 5'UTR [59]. This speculative order of events has some similarities to the proto-gene hypothesis of Carvunis et al. [39], which deals with the potential de novo origin of short genes in intergenic regions of the yeast $S$. cerevisiae.

In EHEC, only two other antiparallel overlapping gene pairs, in which a young gene also may have originated recently de novo by overprinting, have been characterized functionally $[13,53]$. For E. coli K12 two additional antiparallel overlapping gene pairs are described, $y g h X /$ $\operatorname{modA}[60]$ and tnpA/ast $A$ [61] respectively, which might have also originated by overprinting. Another OLG pair exists in Streptomyces coelicolor: The knock-outs of the antiparallel overlapping genes $d m d R I$ and $a d m$ both show a phenotype [11]. In addition, in Bacillus subtilis an annotated OLG pair exists [62].

Whether de novo birth of genes in antisense to annotated genes is more frequent than presumed is still open for discussion, but has been suggested by Haycocks and Grainger [63] based on the frequent binding of transcriptional regulators in intragenic locations. In contrast, a gene duplication followed by neofunctionalization or subfunctionalization, which is the established theory for the origin of new genes [20], produces just variants of existing sequences, overprinting would allow for the rapid creation of true novelty [64].

\section{Conclusion}

Strand-specific RNAseq and RIBOseq are well suited to identify translated ORFs located in antisense to annotated genes. Frequent antisense transcription is observed in all RNAseq experiments, but almost all signals have been interpreted as ncRNA [65]. However, RIBOseq already confirmed translation of many antisense RNAs in eukaryotes [66-68], and this method identified 
numerous overlooked small genes in the intergenic regions of different bacteria [69-71]. Therefore, improved genome annotation algorithms are required which do not systematically dismiss small and/or overlapping genes $[8,72,73]$. Integration of transcriptomic, translatomic, and other experimental data into annotation pipelines would increase specificity and sensitivity for the prediction of novel small genes [74-76]. Additionally, improved proteomic methods are necessary, which do not miss small non-annotated proteins [77, 78]. In any case, functional characterization of novel short genes overlooked to date presents a major future challenge to experimental microbiology. In this paper, we provide initial functional characterization and evidence for overprinting of a small protein encoded in antisense to an annotated protein-coding gene. We assume such overprinting events could be significant for EHEC (e.g., [13, 14]) and maybe other bacteria.

\section{Additional files}

Additional file 1: Table S1. Bacterial strains and plasmids used in this study. (DOCX $16 \mathrm{~kb}$ )

Additional file 2: Table S2. Oligonucleotides used in this study. Restriction enzyme cut sites are highlighted in bold. (DOCX $19 \mathrm{~kb}$ )

Additional file 3: Ratio in percent of EHEC wild type to EHEC $\triangle$ laoB after competitive growth at different growth conditions. Neither the wild type nor the mutant show a significant growth advantage at any of the depicted conditions. The experiment was performed in triplicate. (PPTX $44 \mathrm{~kb}$ )

Additional file 4: Phylogenetic analysis of $l a O B$ at the DNA level. Start codons are colored in blue and stop codons in purple. (PPTX $1172 \mathrm{~kb}$ )

Additional file 5: Phylogenetic analysis of ECs5115 by the Maximum Likelihood method. The tree with the highest log likelihood $(-61,042.2643)$ is shown. The percentage of trees in which the associated taxa clustered together is shown next to the branches. Initial tree(s) for the heuristic search were obtained by applying the Neighbor-Joining method to a matrix of pairwise distances estimated using the Maximum Composite Likelihood (MCL) approach. A discrete Gamma distribution was used to model evolutionary rate differences among sites ( 5 categories; $+G$, parameter $=0.5123$ ). The rate variation model allowed some sites to be evolutionarily invariable $(+1,32.8153 \%$ sites $)$. The tree is drawn to scale, with branch lengths measured in the number of substitutions per site. The analysis involved 30 nucleotide sequences. All positions containing gaps and missing data were eliminated. There was a total of 8025 positions in the final dataset. Evolutionary analyses were conducted in MEGA6. In the alignment to the right, start codons are highlighted in blue and stop codons with a red asterisk. (PPTX $614 \mathrm{~kb}$ )

\footnotetext{
Abbreviations

AA: Amino acid(s); BHI: Brain-heart infusion; bp: Base pair(s); Cl: Competitive index; EGFP: Enhanced green fluorescent protein; IPTG: Isopropyl- $\beta$-D-1thiogalactopyranoside; laoB: L-arginine responsive overlapping gene; LB: Luria-Bertani; LDF: Linear discriminant functions; MOD medium: Modified Bacillus-growth medium; ncRNA: non-coding RNA; $\mathrm{OD}_{600}$ : Optical density at 600 nm; OLG: Overlapping gene; ORF: Open reading frame; PBS: Phosphatebuffered saline; PCR: Polymerase chain reaction; RACE: Rapid amplification of copy-DNA ends; RCV: Ribosomal coverage value; RIBOseq: Ribosomalfootprint sequencing; RNAseq: RNA sequencing; RPKM: Reads per kilobase per million mapped reads; rpm: Rounds per minute; SD: Shine-Dalgarno; TSS: Transcription start site; UTR: Untranslated region
}

\section{Acknowledgements}

Not applicable.

\section{Funding}

This work was funded by the Deutsche Forschungsgemeinschaft DFG (KE740/13-1,2,3, and SCHE316/3-1,2,3). The funding body had neither a role in the design of the study, nor in collection, analysis, and interpretation of data, or in writing the manuscript.

\section{Availability of data and materials}

All data generated or analyzed during this study are included in this published article and its supplementary information files. The sequencing raw data used from [26] is available at the Sequence Read Archive (SRA, NCBI) under the accession SRP113660.

\section{Authors' contributions}

SMH, SSch and KN designed and planned the study. SMH performed the $3^{\prime}$ and 5'RACE experiments, the promoter activity assays, the competitive growth experiments and the complementation. SSi identified the optimal position for the strand-specific knock-out mutant and RW cloned the mutants. IAS performed the expression of the EGFP-LaoB fusion proteins. Data from those experiments were analyzed by SMH with the help of SSi, RW and IAS. SV did the phylostratigraphic analysis of the overlapping gene pair. SMH drafted the manuscript with the help of all other authors. SSch and KN supervised writing and critically edited the manuscript. All authors have read and approved the manuscript.

\section{Ethics approval and consent to participate}

Not applicable.

\section{Consent for publication}

Not applicable.

\section{Competing interests}

The authors declare that they have no competing interests.

\section{Publisher's Note}

Springer Nature remains neutral with regard to jurisdictional claims in published maps and institutional affiliations.

\section{Author details}

${ }^{1}$ Chair for Microbial Ecology, Wissenschaftszentrum Weihenstephan, Technische Universität München, Weihenstephaner Berg 3, 85354 Freising, Germany. ${ }^{2}$ Department of Computer and Information Science, University of Konstanz, Box 78, 78457 Konstanz, Germany. ${ }^{3}$ ZIEL - Institute for Food \& Health, Technische Universität München, Weihenstephaner Berg 3, 85354 Freising, Germany. ${ }^{4}$ Core Facility Microbiome/NGS, ZIEL - Institute for Food \& Health, Technische Universität München, Weihenstephaner Berg 3, 85354 Freising, Germany. ${ }^{5}$ Fraunhofer ITEM-R, Am Biopark 9, 93053 Regensburg, Germany.

Received: 22 June 2017 Accepted: 31 January 2018

Published online: 12 February 2018

\section{References}

1. Krakauer DC. Stability and evolution of overlapping genes. Evolution. 2000; 54(3):731-9.

2. Caliskan N, Katunin VI, Belardinelli R, Peske F, Rodnina MV. Programmed -1 frameshifting by kinetic partitioning during impeded translocation. Cell. 2014;157(7):1619-31.

3. Meydan S, Klepacki D, Karthikeyan S, Margus T, Thomas P, Jones JE, Khan Y, Briggs J, Dinman JD, Vazquez-Laslop N, et al. Programmed ribosomal frameshifting generates a copper transporter and a copper chaperone from the same gene. Mol Cell. 2017;65(2):207-19.

4. Sharma V, Firth AE, Antonov I, Fayet O, Atkins JF, Borodovsky M, Baranov PV. A pilot study of bacterial genes with disrupted ORFs reveals a surprising profusion of protein sequence recoding mediated by ribosomal frameshifting and transcriptional realignment. Molecular biology and evolution. 2011;28(11):3195-211.

5. Merino E, Balbas P, Puente JL, Bolivar F. Antisense overlapping open reading frames in genes from bacteria to humans. Nucleic Acids Res. 1994;22(10): 1903-8. 
6. Mir K, Neuhaus K, Scherer S, Bossert M, Schober S. Predicting statistical properties of open reading frames in bacterial genomes. PLoS One. 2012; 7(9):e45103.

7. Veloso F, Riadi G, Aliaga D, Lieph R, Holmes DS. Large-scale, multi-genome analysis of alternate open reading frames in bacteria and archaea. OMICS. 2005;9(1):91-105.

8. Firth $A E$, Brown CM. Detecting overlapping coding sequences with pairwise alignments. Bioinformatics. 2005;21(3):282-92.

9. Lèbre S, Gascuel O. The combinatorics of overlapping genes. J Theor Biol. 2017;415:90-101.

10. Johnson ZI, Chisholm SW. Properties of overlapping genes are conserved across microbial genomes. Genome Res. 2004;14(11):2268-72

11. Tunca S, Barreiro C, Coque JJ, Martin JF. Two overlapping antiparallel genes encoding the iron regulator DmdR1 and the Adm proteins control siderophore and antibiotic biosynthesis in Streptomyces coelicolor A3(2). FEBS J. 2009;276(17):4814-27.

12. Silby MW, Levy SB. Overlapping protein-encoding genes in Pseudomonas fluorescens PfO-1. PLoS Genet. 2008;4(6):e1000094.

13. Fellner L, Bechtel N, Witting MA, Simon S, Schmitt-Kopplin P, Keim D, Scherer S, Neuhaus K. Phenotype of htgA (mbiA), a recently evolved orphan gene of Escherichia coli and Shigella, completely overlapping in antisense to yaaW. FEMS Microbiol Lett. 2014;350(1):57-64.

14. Fellner L, Simon S, Scherling C, Witting M, Schober S, Polte C, SchmittKopplin P, Keim DA, Scherer S, Neuhaus K. Evidence for the recent origin of a bacterial protein-coding, overlapping orphan gene by evolutionary overprinting. BMC Evol Biol. 2015;15(1):283.

15. Rancurel C, Khosravi M, Dunker AK, Romero PR, Karlin D. Overlapping genes produce proteins with unusual sequence properties and offer insight into de novo protein creation. J Virol. 2009;83(20):10719-36.

16. Loessner MJ, Gaeng S, Scherer S. Evidence for a holin-like protein gene fully embedded out of frame in the endolysin gene of Staphylococcus aureus bacteriophage 187. J Bacteriol. 1999;181(15):4452-60.

17. Chirico N, Vianelli A, Belshaw R. Why genes overlap in viruses. Proc Royal Soc B: Biol Sci. 2010;277(1701):3809-17.

18. Keese PK, Gibbs A. Origins of genes: "big bang" or continuous creation? Proc Natl Acad Sci U S A. 1992;89(20):9489-93.

19. Boldogköirid Z. Coding in the noncoding DNA strand: a novel mechanism of gene evolution? J Mol Evol. 2000;51(6):600-6.

20. Kondrashov FA. Gene duplication as a mechanism of genomic adaptation to a changing environment. Proc Biol Sci. 2012;279(1749):5048-57.

21. Hücker SM, Simon S, Scherer S, Neuhaus K. Transcriptional and translational regulation by RNA thermometers, riboswitches and the sRNA DsrA in Escherichia coli 0157:H7 Sakai under combined cold and osmotic stress adaptation. FEMS Microbiol Lett. 2017;364(2)

22. Hayashi T, Makino K, Ohnishi M, Kurokawa K, Ishii K, Yokoyama K, Han CG, Ohtsubo E, Nakayama K, Murata T, et al. Complete genome sequence of enterohemorrhagic Escherichia coli 0157:H7 and genomic comparison with a laboratory strain K-12. DNA Res. 2001;8(1):11-22.

23. Miller WG, Leveau JH, Lindow SE. Improved gfp and inaZ broad-host-range promoter-probe vectors. Mol Plant-Microbe Interact. 2000;13(11):1243-50.

24. Rosenfeld E, Duport C, Zigha A, Schmitt P. Characterization of aerobic and anaerobic vegetative growth of the food-borne pathogen Bacillus cereus F4430/73 strain. Can J Microbiol. 2005;51(2):149-58.

25. Kim J, Webb AM, Kershner JP, Blaskowski S, Copley SD. A versatile and highly efficient method for scarless genome editing in Escherichia coli and Salmonella enterica. BMC Biotechnol. 2014;14:84.

26. Hücker SM, Ardern Z, Goldberg T, Schafferhans A, Bernhofer M, Vestergaard G, Nelson CW, Schloter M, Rost B, Scherer S. Discovery of numerous novel small genes in the intergenic regions of the Escherichia coli 0157:H7 Sakai genome. PLoS One. 2017;12(9):e0184119.

27. Rutherford K, Parkhill J, Crook J, Horsnell T, Rice P, Rajandream MA, Barrell B. Artemis: sequence visualization and annotation. Bioinformatics. 2000;16(10):944-5.

28. Solovyev W, Tatarinova TV. Towards the integration of genomics, epidemiological and clinical data. Genome Med. 2011;3(7):48.

29. Yu HH, Di Russo EG, Rounds MA, Tan M. Mutational analysis of the promoter recognized by Chlamydia and Escherichia coli $\sigma^{28}$ RNA polymerase. J Bacteriol. 2006;188(15):5524-31.

30. Nonaka G, Blankschien M, Herman C, Gross CA, Rhodius VA. Regulon and promoter analysis of the $E$. coli heat-shock factor, $\sigma^{32}$, reveals a multifaceted cellular response to heat stress. Genes Dev. 2006;20(13):1776-89.
31. Burrows PC, Severinov K, Ishihama A, Buck M, Wigneshweraraj SR. Mapping $\sigma^{54}$-RNA polymerase interactions at the -24 consensus promoter element. J Biol Chem. 2003;278(32):29728-43.

32. Ma J, Campbell A, Karlin S. Correlations between Shine-Dalgarno sequences and gene features such as predicted expression levels and operon structures. J Bacteriol. 2002;184(20):5733-45.

33. Altschul SF, Gish W, Miller W, Myers EW, Lipman DJ. Basic local alignment search tool. J Mol Biol. 1990;215(3):403-10.

34. Yachdav G, Kloppmann E, Kajan L, Hecht M, Goldberg T, Hamp T, Honigschmid P, Schafferhans A, Roos M, Bernhofer M, et al. PredictProteinan open resource for online prediction of protein structural and functional features. Nucleic Acids Res. 2014;42(Web Server issue):W337-43.

35. Rost B, Sander C. Combining evolutionary information and neural networks to predict protein secondary structure. Proteins. 1994;19(1):55-72.

36. Bernhofer M, Kloppmann E, Reeb J, Rost B. TMSEG: novel prediction of transmembrane helices. Proteins. 2016;84(11):1706-16.

37. Ceroni A, Passerini A, Vullo A, Frasconi P. DISULFIND: a disulfide bonding state and cysteine connectivity prediction server. Nucleic Acids Res. 2006; 34(suppl 2):W177-81.

38. Goldberg T, Hecht M, Hamp T, Karl T, Yachdav G, Ahmed N, Altermann U, Angerer $\mathrm{P}$, Ansorge S, Balasz K, et al. LocTree3 prediction of localization. Nucleic Acids Res. 2014;42(Web Server issue):W350-5.

39. Carvunis AR, Rolland T, Wapinski I, Calderwood MA, Yildirim MA, Simonis N, Charloteaux B, Hidalgo CA, Barbette J, Santhanam B, et al. Proto-genes and de novo gene birth. Nature. 2012;487(7407):370-4.

40. Domazet-Lošo T, Tautz D. An ancient evolutionary origin of genes associated with human genetic diseases. Mol Biol Evol. 2008;25(12):2699-707.

41. Tamura K, Stecher G, Peterson D, Filipski A, Kumar S. MEGA6: molecular evolutionary genetics analysis version 6.0. Mol Biol Evol. 2013;30(12):2725-9.

42. Li W, Cowley A, Uludag M, Gur T, McWilliam H, Squizzato S, Park YM, Buso $\mathrm{N}$, Lopez R. The EMBL-EBI bioinformatics web and programmatic tools framework. Nucleic Acids Res. 2015;43(W1):W580-4.

43. Neuhaus K, Landstorfer R, Simon S, Schober S, Wright PR, Smith C, Backofen R, Wecko R, Keim DA, Scherer S. Differentiation of ncRNAs from small mRNAs in Escherichia coli 0157:H7 EDL933 (EHEC) by combined RNAseq and RIBOseq - ryhB encodes the regulatory RNA RyhB and a peptide, RyhP. BMC Genomics. 2017;18(1):216.

44. Ingolia NT, Ghaemmaghami S, Newman JR, Weissman JS. Genome-wide analysis in vivo of translation with nucleotide resolution using ribosome profiling. Science. 2009;324(5924):218-23.

45. Liu B, Qian SB. Characterizing inactive ribosomes in translational profiling. Translation. 2016:4(1):e1138018.

46. Bobrovskyy M, Vanderpool CK. Regulation of bacterial metabolism by small RNAs using diverse mechanisms. Annu Rev Genet. 2013;47:209-32.

47. Koo BM, Rhodius VA, Campbell EA, Gross CA. Dissection of recognition determinants of Escherichia coli $\sigma^{32}$ suggests a composite -10 region with an 'extended -10 ' motif and a core -10 element. Mol Microbiol. 2009;72(4): $815-29$.

48. Cunin R, Glansdorff N, Pierard A, Stalon V. Biosynthesis and metabolism of arginine in bacteria. Microbiol Rev. 1986;50(3):314-52.

49. Wissenbach U, Six S, Bongaerts J, Ternes D, Steinwachs S, Unden G. A third periplasmic transport system for L-arginine in Escherichia coli: molecular characterization of the artPIQMJ genes, arginine binding and transport. Mol Microbiol. 1995;17(4):675-86.

50. Hemm MR, Paul BJ, Schneider TD, Storz G, Rudd KE. Small membrane proteins found by comparative genomics and ribosome binding site models. Mol Microbiol. 2008;70(6):1487-501.

51. Kemp G, Cymer F. Small membrane proteins-elucidating the function of the needle in the haystack. Biol Chem. 2014;395(12):1365-77.

52. Pavesi A, Magiorkinis G, Karlin DG. Viral proteins originated de novo by overprinting can be identified by codon usage: application to the "gene nursery" of Deltaretroviruses. PLoS Comput Biol. 2013;9(8):e1003162.

53. Delaye L, Deluna A, Lazcano A, Becerra A. The origin of a novel gene through overprinting in Escherichia coli. BMC Evol Biol. 2008;8(1):31.

54. Huvet M, Stumpf MP. Overlapping genes: a window on gene evolvability. BMC Genomics. 2014;15(1):721.

55. Lim JY, Yoon J, Hovde CJ. A brief overview of Escherichia coli O157:H7 and its plasmid 0157. J Microbiol Biotechnol. 2010;20(1):5-14.

56. Duffitt AD, Reber RT, Whipple A, Chauret C. Gene expression during survival of Escherichia coli O157:H7 in soil and water. Int J Microbiol. 2011;2011: 340506. 
57. Landstorfer R, Simon S, Schober S, Keim D, Scherer S, Neuhaus K. Comparison of strand-specific transcriptomes of enterohemorrhagic Escherichia coli 0157:H7 EDL933 (EHEC) under eleven different environmental conditions including radish sprouts and cattle feces. BMC Genomics. 2014;15:353.

58. Lillo F, Krakauer DC. A statistical analysis of the three-fold evolution of genomic compression through frame overlaps in prokaryotes. Biol Direct. 2007;2(1):22.

59. Fonseca MM, Harris DJ, Posada D. Origin and length distribution of unidirectional prokaryotic overlapping genes. G3. 2014;4(1):19-27.

60. Kurata T, Katayama A, Hiramatsu M, Kiguchi Y, Takeuchi M, Watanabe T, Ogasawara H, Ishihama A, Yamamoto K. Identification of the set of genes, including nonannotated morA, under the direct control of ModE in Escherichia coli. J Bacteriol. 2013;195(19):4496-505.

61. McVeigh A, Fasano A, Scott DA, Jelacic S, Moseley SL, Robertson DC, Savarino SJ. IS1414, an Escherichia coli insertion sequence with a heat-stable enterotoxin gene embedded in a transposase-like gene. Infect Immun. 2000;68(10):5710-5.

62. Wang LF, Park SS, Doi RH. A novel Bacillus subtilis gene, antE, temporally regulated and convergent to and overlapping dnaE. J Bacteriol. 1999;181(1): 353-6.

63. Haycocks JR, Grainger DC. Unusually situated binding sites for bacterial transcription factors can have hidden functionality. PLoS One. 2016;11(6): e0157016.

64. Neme R, Tautz D. Phylogenetic patterns of emergence of new genes support a model of frequent de novo evolution. BMC Genomics. 2013;14:117.

65. Dornenburg JE, Devita AM, Palumbo MJ, Wade JT. Widespread antisense transcription in Escherichia coli. MBio. 2010;1(1)

66. Aspden JL, Eyre-Walker YC, Phillips RJ, Amin U, Mumtaz MA, Brocard M, Couso JP. Extensive translation of small ORFs revealed by poly-Ribo-Seq. elife. 2014;3:e03528.

67. Bazzini AA, Johnstone TG, Christiano R, Mackowiak SD, Obermayer B, Fleming ES, Vejnar CE, Lee MT, Rajewsky N, Walther TC, et al. Identification of small ORFs in vertebrates using ribosome footprinting and evolutionary conservation. EMBO J. 2014;33(9):981-93.

68. Carlevaro-Fita J, Rahim A, Guigo R, Vardy LA, Johnson R. Cytoplasmic long noncoding RNAs are frequently bound to and degraded at ribosomes in human cells. RNA. 2016;22(6):867-82.

69. Jeong Y, Kim JN, Kim MW, Bucca G, Cho S, Yoon YJ, Kim BG, Roe JH, Kim SC, Smith CP, et al. The dynamic transcriptional and translational landscape of the model antibiotic producer Streptomyces coelicolor A3(2). Nat Commun. 2016;7:11605.

70. Baek J, Lee J, Yoon K, Lee H. Identification of unannotated small genes in Salmonella. G3. 2017;7(3):983-9.

71. Neuhaus K, Landstorfer R, Fellner L, Simon S, Marx H, Ozoline O, Schafferhans A, Goldberg T, Rost B, Küster B, et al. Translatomics combined with transcriptomics and proteomics reveals novel functional, recently evolved orphan genes in Escherichia coli 0157:H7 (EHEC). BMC Genomics. 2016;7:133.

72. Warren AS, Archuleta J, Feng WC, Setubal JC. Missing genes in the annotation of prokaryotic genomes. BMC Bioinformatics. 2010;11:131.

73. ÓhÉigeartaigh SS, Armisén D, Byrne KP, Wolfe KH. SearchDOGS bacteria, software that provides automated identification of potentially missed genes in annotated bacterial genomes. J Bacteriol. 2014;196(11):2030-42.

74. Karp PD, Keseler IM, Shearer A, Latendresse M, Krummenacker M, Paley SM, Paulsen I, Collado-Vides J, Gama-Castro S, Peralta-Gil M, et al. Multidimensional annotation of the Escherichia coli K-12 genome. Nucleic Acids Res. 2007;35(22):7577-90.

75. Salgado H, Peralta-Gil M, Gama-Castro S, Santos-Zavaleta A, MunizRascado L, Garcia-Sotelo JS, Weiss V, Solano-Lira H, Martinez-Flores I, Medina-Rivera A, et al. RegulonDB v8.0: omics data sets, evolutionary conservation, regulatory phrases, cross-validated gold standards and more. Nucleic Acids Res. 2013;41(Database issue):D203-13.

76. Olexiouk V, Crappe J, Verbruggen S, Verhegen K, Martens L, Menschaert G. SORFs.org: a repository of small ORFs identified by ribosome profiling. Nucleic Acids Res. 2016:44(D1):D324-9.
77. Zur H, Aviner R, Tuller T. Complementary post transcriptional regulatory information is detected by PUNCH-P and ribosome profiling. Sci Rep. 2016; 6:21635.

78. Willems P, Ndah E, Jonckheere V, Stael S, Sticker A, Martens L, Van Breusegem F, Gevaert K, Van Damme P. N-terminal proteomics assisted profiling of the unexplored translation initiation landscape in Arabidopsis thaliana. Mol Cell Proteomics. 2017;16(6):1064-80.

\section{Submit your next manuscript to BioMed Central and we will help you at every step:}

- We accept pre-submission inquiries

- Our selector tool helps you to find the most relevant journal

- We provide round the clock customer support

- Convenient online submission

- Thorough peer review

- Inclusion in PubMed and all major indexing services

- Maximum visibility for your research

Submit your manuscript at www.biomedcentral.com/submit
Biomed Central 